\title{
The Effect of Photobiomodulation Therapy on the Differentiation, Proliferation, and Migration of the Mesenchymal Stem Cell: A Review
}

\author{
Behnaz Ahrabi ${ }^{1}$, Mostafa Rezaei Tavirani ${ }^{2}$, Maryam Sadat Khoramgah ${ }^{1}$, Mohsen Noroozian ${ }^{1,3}$, Shahram \\ Darabi $^{4}$, Shahrokh Khoshsirat ${ }^{* *}$, Hojjat Allah Abbaszadeh ${ }^{1,5^{*}}$
}

${ }^{1}$ Laser Application in Medical Sciences Research Center, Shahid Beheshti University of Medical Sciences, Tehran, Iran ${ }^{2}$ Proteomics Research Center, Faculty of Paramedical Sciences, Shahid Beheshti University of Medical Sciences, Tehran, Iran ${ }^{3}$ Department of Biology and Anatomical Sciences, School of Medicine, Shahid Beheshti University of Medical Sciences, Tehran, Iran

${ }^{4}$ Cellular and Molecular Research Center, Qazvin University of Medical Science, Qazvin, Iran

${ }^{5}$ Hearing Disorders Research Center, Loghman Hakim Hospital, Shahid Beheshti University of Medical Sciences, Tehran, Iran

\author{
*Correspondence to \\ Hojjat Allah Abbaszadeh, Laser \\ Application in Medical Sciences \\ Research Center, Shahid Beheshti \\ University of Medical Sciences, \\ Tehran, Iran \\ Email: Dr.Abbaszadeh@sbmu.ac.ir \\ Shahrokh Khoshsirat, Hearing \\ Disorders Research Center, Loghman \\ Hakim Hospital, Shahid Beheshti \\ University of Medical Sciences, \\ Tehran, Iran \\ Email: Dr_khoshsirat@yahoo.com
}

Published online December 1, 2019

\begin{abstract}
Introduction: The purpose of this study is to investigate the effect of a low-power laser on the proliferation, migration, differentiation of different types of mesenchymal stem cells (MSCs) in different studies.

Methods: The relevant articles that were published from 2004 to 2019 were collected from the sources of PubMed, Scopus, and only the articles specifically examining the effect of a lowpower laser on the proliferation, differentiation, and migration of the MSCs were investigated. Results: After reviewing the literature, only 42 articles were found relevant. Generally, most of the studies demonstrated that different laser parameters increased the proliferation, migration, and differentiation of the MSCs, except the results of two studies which were contradictory. In fact, changing the parameters of a low-power laser would affect the results. On the other hand, the source of the stem cells was reported as a key factor. In addition, the combination of lasers with other therapeutic approaches was found to be more effective.

Conclusion: The different parameters of lasers has been found to be effective in the proliferation, differentiation, and migration of the MSCs and in general, a low-power laser has a positive effect on the MSCs, helping to improve different disease models.

Keywords: Photobiomodulation therapy; Differentiation; Proliferation; Migration; Mesenchymal stem cell.
\end{abstract}

\section{Introduction}

The absorption and utilization of vitamins, circadian rhythms, and sleep-wake cycles are examples of the lightdependent systems that show the role of the light in the biological systems. ${ }^{1}$ The invention of the LASER (light amplification with stimulated emission of radiation) provided the opportunity to obtain high-power light at specific wavelengths and facilitated its application in biology and allowed a new field of research into the biological effects of radiation on animals and humans. ${ }^{2}$ Low-level laser therapy (LLLT) was discovered in the 1960s and was first used by the National Aeronautics and Space Administration (NASA) in order to accelerate wound healing in the space. ${ }^{3} \mathrm{PBM}$, or phot-modulation or a low-power laser is a non-invasive and non-toxic phototherapy that its wavelength is within the region of the red to near-infrared spectrum in the range of 600 to 1000 $\mathrm{nm}$. Its beneficial effects have been observed in a variety of diseases and physiological processes, including wound healing, hypoxic damage, and cerebral regeneration. Photo-modulation is biologically attributed to light absorption by the internal photoreceptor of the respiratory chain in the mitochondria, which induces mitochondrial activation within cells. ${ }^{3-5}$ At the cellular and molecular level, photons transmitted from a low-power laser can be absorbed by mitochondria, leading to an increase in the production of ATP. ${ }^{6}$ It has been well-established that the bio-stimulatory effects of the laser are influenced by the following parameters: wavelength, energy density, power output, frequency/duration of irradiation, distance cells and laser spot/probe. ${ }^{7,8}$ In most of the studies, the laser parameters may be different which could be resulted

Please cite this article as follows: Ahrabi B, Rezaei Tavirani M, Khoramgah MS, Noroozian M, Darabi S, Khoshsirat S, et al. The effect of photobiomodulation therapy on the differentiation, proliferation, and migration of the mesenchymal stem cell: a review. J Lasers Med Sci. 2019;10(suppl 1):S96-S103. doi:10.15171/jlms.2019.S17. 
in distinct effects. Evidence has shown that when the mesenchymal stem cells (MSCs) derived from adipose tissue are irradiated with $5 \mathrm{~J} / \mathrm{cm}^{2}$, the proliferation and secretion of these cells increase substantially. ${ }^{6}$ The commonly reported PBM devices include helium-neon gas lasers, gallium-arsenide, neodymium-doped yttrium aluminum garnet, gallium aluminum arsenide (GaAlAs), indium gallium aluminum phosphide diode lasers, nonthermal, non-ablative carbon dioxide lasers, LED arrays, and visible light. ${ }^{9}$

\section{The Molecular Mechanism of a Low-Level Laser on Proliferation and Migration}

TPKR/Ras/Raf/MEK/ERK/Mnk1/eIF4E/CyclinD1 Pathway

Studies have shown that low-power lasers can induce TPKR (tyrosine-protein kinase receptor) like c-MET, which can activate the MAPK/ERK signaling pathway, thereby it may induce cell proliferation. EIF4E (eukaryotic initiation factor $4 \mathrm{E}$ ) is a major regulator of cap-dependent mRNA that responds to various stimuli, including hormones, growth factors, and mitogens. On the other hand, low-level lasers can phosphorylate PHAS-1 (protein heat and acid-stable) and upregulate the expression of eIF4E, CyclinD, and also increases the proliferation of cells. EIF4E can also be directly phosphorylated by MNK1 and MNK2. ${ }^{10,11}$

\section{TPKR/PI3K/Akt/mTOR/eIF4E Pathway}

PI3K phosphorylation is the most important downstream TPKR pathway. A low-level laser can increase the phosphorylation of Akt and the PI3K pathway, which induces the phosphorylation of PHAS-1 through the phosphorylation of mTOR and activates proliferation and cell migration through Elf4e phosphorylation. ${ }^{10,12-14}$

\section{PI3K/Akt/eNOS Pathway}

Nitric oxide (NO) has the capacity to increase angiogenesis and vasculogenesis. In fact, eNOS signaling pathway could result in a low level of NO. A low-power laser at $632.5 \mathrm{~nm}$ can enhance eNOS expression in endothelial cells, thereby promoting endothelial cell proliferation and migration, which plays an important role in angiogenesis. ${ }^{10,15,16}$

\section{TPKR/PLC-gamma/PKC Pathway}

The activation of PLC can catalyze phospholipids, thereby increasing the concentration of DAG, IP3. IP3 can increase calcium from the endoplasmic reticulum that activates PKC. PKC will be effective in cell proliferation, tumor proliferation, and the differentiation and apoptosis of cells. The low-power laser of $632.5 \mathrm{~nm}$ showed that it can increase calcium, thereby helping the proliferation of cells. ${ }^{10,17,18}$

\section{$\Delta \Psi \mathrm{m} / \mathrm{ATP} / \mathrm{cAMP} / \mathrm{JNK} / \mathrm{AP}-1$ Pathway}

The low-level laser could result in an increase in cAMP and consequently $\mathrm{jNK}$ phosphorylation, thereby increasing AP1. AP-1 enhances the expression of the genes involved in proliferation, survival, and angiogenesis. ${ }^{10,19,20}$

\section{ROS/Src Pathway}

The low-power laser can increase ROS which regulates the activity of different protein kinases. Src serves as a target for ROS, which has a specific role in various cellular processes, including proliferation, migration and cell survival. ${ }^{10,21}$

\section{Bcl-2, Bax, p53, and p21}

The activated p53 can inhibit growth and induce apoptosis by upregulating the expression of BAX and P21 genes. $\mathrm{Bcl}-2$ has been suggested as a regulator of the apoptotic pathway in which a low-power laser can increase the expression of BCL2 proteins and decrease the expression of BAX protein. ${ }^{10,22}$

The ISCT for the MSCs offers at least three standard criteria which include adhesion to the plate, an increase in the expression of surface molecules, and differentiation into three classes.

The purpose of this study was to summarize the results of the studies that have pointed toward the proliferation of these cells and their power of differentiation. ${ }^{4}$ A lowpower laser has the potential to be effective in the biological function of the MSCs. Therefore, the application of lowlevel laser could be effective in accelerating bone fractures, wound healing, neuroregeneration, blood disorders, pain and inflammation, and dermatological treatments. ${ }^{23,24}$ It can also increase the therapeutic power of the adipose mesenchymal cells to treat the scar and fibrosis. ${ }^{6}$

\section{The Variety of Mesenchymal Stem Cells}

Umbilical Cord-Mesenchymal Stem Cells

Using the photo-modulation or the low-power laser can increase proliferation and self-renewal function in the umbilical cord MSCs by increasing the expression of embryonic stem cell-associated genes such as Nanog, oct 4 , and sox 2 . This study also showed that the colony which formed the quality of the MSCs increased with low-level laser radiation and the differentiation properties of adipogenic and osteogenic in the MSCs were not different. Also, there was no difference in the level of adipogenic marker mRNA (PPARI, LPL) and the osteogenic marker (ALP, BGLAP) in the MSCs compared to the control group. In order to investigate mitochondrial activity in the MSCs, it has been shown that the intensity mean of rhodamin 123 fluorescence increases significantly compared to the laser-free MSCs. ${ }^{23,25}$ Angiogenic properties increase significantly in the underlying laser MSCs by increasing the expression of angiogenesis-related genes (VEGF, PDGF, HGF, BFGF, ANGPT1, ANGPT2, SDF-a1), which can damage endothelial cells and can significantly increase total tube length and branch point compared to the laser-free MSCs. The study showed that 
low-level laser irradiation could increase angiogenesis by the inhibition of apoptosis in the mesenchymal stem. ${ }^{4}$ The results from a study also showed that using an 808 $\mathrm{nm}$ laser could induce the neural differentiation of the umbilical cord MSCs to the neuron cells. The study also found that only an $808 \mathrm{~nm}$ laser could express the NeuN marker protein of neurons in 72 hours and a $635 \mathrm{~nm}$ laser increased the proliferation of the mesenchymal cells. ${ }^{25} \mathrm{~A}$ laser with a wavelength of $635 \mathrm{~nm}$ amplified the umbilical cord mesenchymal cells if it proved that a low-power laser with $808 \mathrm{~nm}$ failed to increase the proliferation of the same cells. ${ }^{26}$

\section{Adipose Mesenchymal Stem Cells}

It has been reported that the toxic effects of doxorubicin on the adipose mesenchymal stem cells can be reduced by using a low-power laser with a wavelength of $660 \mathrm{~nm}$, output power of $30 \mathrm{~mW}$, a laser beam of $0.028 \mathrm{~cm}^{2}$, and irradiation of $1.07 \mathrm{~mW} / \mathrm{cm}^{2}$. A Low-power laser with these features increases the viability of the MSCs and inhibits apoptosis and oxidative stress in the MSCs that are treated with doxorubicin. A low-power laser (0.2, 0.4 , and 0.7 ) can restore the modified morphology of the treated cells with doxorubicin compared to the normal cells. Furthermore, IL-6 cytokine levels significantly increase by low-level laser radiation compared to the control group. ${ }^{27}$ Also, after the injection of the low-power laser mediated MSCs, the migration of the mesenchymal cells to the damaged tendon of the calcaneal tendons was elevated in rats in comparison with the laser alone, and the expression of the collagen III and IL- 10 increased. In this study, no difference was observed in the amount of TNFa cytokines among the groups. ${ }^{28}$ The GaAlAs laser $\left(650 \mathrm{~nm}, 4 \mathrm{~J} / \mathrm{cm}^{2}\right)$ improved the repair in mouse model of skin photoaging by increasing the proliferation, differentiation, and secretion of the growth factor of the MSCs. Furthermore, the expression of the mesenchymal surface markers increased. ${ }^{5}$

A transplantation skin flap is used for skin lesions in plastic surgery. After the skin is removed from the donor, it is possible to discontinue the flow of vessels and the angiogenic growth factors are very important. A study showed that a low-power laser $(660 \mathrm{~nm} \pm 20 \mathrm{~nm}, 6 \mathrm{~J} /$ $\mathrm{cm}^{2}, 10 \mathrm{mV} / \mathrm{cm}^{2}$ ) could increase angiogenic factors in the adipose MSCs, and after transplantation, it was revealed that it could differentiate endothelial cells and improve function. ${ }^{29}$ This study also showed that apoptosis was reduced in the adipose MSCs after being treated with a low-power laser. After identification of CD31, CD34, vWF, and KD markers by using immunofluorescence, the differentiation of the MSCs into the endothelial cells was confirmed..$^{30,31}$ A low-power laser (wavelength: $660 \mathrm{~nm}+20 \mathrm{~nm}, 220 \mathrm{~V}+22 \mathrm{~V}, 50 \mathrm{~Hz}$ ) can increase cell migration by increasing EKK1/2, and FAK which regulates cell adhesion and migration signals in cells. The studies also showed that the proliferation and viability of the MSCs increased. In this study, the growth factors of HGF and PDGF were also elevated. ${ }^{20}$ The use of a lowpower laser $\left(808 \mathrm{~nm}, 3 \mathrm{~J} / \mathrm{cm}^{2}, 200 \mathrm{mV}, 0.2 \mathrm{~W} / \mathrm{cm}^{2}\right)$ for seven days and 5 minutes with electromagnetic increased the proliferation and viability of the cells. ${ }^{32}$ After coculturing the adipose MSCs with smooth muscle cells, the proliferation and viability of the MSCs and the differentiation of the MSCs into smooth muscle cells was increased, but application of the low-power laser $(636 \mathrm{~nm}$, $5 \mathrm{~J} / \mathrm{cm}^{2}$ ) significantly increased the differentiation of the MSCs (33). The effect of a low-power laser (660 nm and $\left.0.5,1 \mathrm{~J} / \mathrm{cm}^{2}\right)$ on the adipose and bone marrow-derived MSCs was dose-dependent and it increased the cell growth and proliferation without any nuclear changes. ${ }^{34}$ Low-power lasers $\left(660 \mathrm{~nm}, 550 \mathrm{~mW} / \mathrm{cm}^{2}\right)$ accelerated the ischemic limb function by accelerating endothelial cell differentiation and secreting growth factors (VEGF, HGF, and FGF).$^{35}$ Using an adipose MSC in an acellular dermal matrix with a low-power laser $\left(632.8 \mathrm{~nm}, 17 \mathrm{~mW}, 1 \mathrm{~J} / \mathrm{cm}^{2}\right)$ significantly improved bone formation and dramatically increased bone mineral density and bone mass volume. ${ }^{36}$

\section{Bone Marrow Mesenchymal Stem Cells}

A study showed that using chloroaluminium phthalocyanine nano-emulsion (AlClPc/NE) with a lowpower laser $\left(20 \mathrm{~mJ} / \mathrm{cm}^{2}\right.$ at $\left.670 \mathrm{~nm}\right)$ for 24 hours could induce the differentiation of the MSCs into the adipose cells. The expression of lipoprotein lipase and PPARY mRNA also increased in this group. The structures of lipid vacuoles were also observed ${ }^{37}$. When the MSCs are used to treat damaged bones, it is essential to differentiate the MSCs into the bone cells, and this has already been studied, which has acknowledged the importance of this matter. ${ }^{38}$ A low-power laser $\left(2\right.$ and $\left.4 \mathrm{~J} / \mathrm{cm}^{2}\right)$ significantly increased the proliferation of the bone marrow MSCs and also differentiated them into the bone cells. Moreover, this study showed that a laser $\left(16 \mathrm{~J} / \mathrm{cm}^{2}\right)$ could significantly suppress proliferation and differentiation into the bones. Low-power lasers of 4,8 , and $16 \mathrm{~J} / \mathrm{cm}^{2}$ also inhibited the expression of $\mathrm{TNFa}^{23}$ Using forskolin with a lowpower laser $\left(20 \mathrm{~mJ} / \mathrm{cm}^{2}\right)$ in the bone marrow MSCs could differentiate them into the neuron cells. The expression of beta-tubulin II protein also increased in this study. ${ }^{24}$

Osteoporosis after menopause is a major concern in a society where bone density in women is reduced which could be resulted in increasing the risk of bone fracture. It was shown that a low-level laser in the osteoporosis MSCs from ovariectomized mice could significantly increase the optical density and cell viability compared to the control group. ${ }^{39,40}$ Also, another study showed that the effects of a low-power laser strongly depended on wavelength parameters, the number of laser therapy sessions, the state of MSC physiology, and the type of the laser. ${ }^{40}$ In Europe, about 1.5 million patients undergo jaw repair every year. Despite surgical interventions, about $20 \%$ of them still have dysfunction. Many studies have shown that the use 
of MSCs in the oro-maxillofacial is very promising. A study also showed that the use of a low-power laser $(808$ $\mathrm{nm}, 64 \mathrm{~J} / \mathrm{cm}^{2}$ ) could increase the expression of RUNX2, ALP, and OSX. RUNX2 is the most important marker for osteoblast differentiation. In this study, the reduction of the pro-inflammatory factors (IL6, IL17) and the increase of anti-inflammatory cytokines (IL-10 and IL1) were observed. ${ }^{41}$ The low-power laser $808 \mathrm{~nm}, 4 \mathrm{~J} / \mathrm{cm}^{2}$ had no effect on the proliferation and differentiation of the MSCs into the osteoblasts and osteoclast cells. ${ }^{42}$ Lowpower lasers $(15 \mathrm{~Hz}, 150 \mathrm{~mJ}, 2.25 \mathrm{~W})$ can proliferate and differentiate the bone marrow MSCs into the osteoblasts cells in 3-dimensional collagen scaffolds that can be used in the treatment of periodontal diseases..$^{43} \mathrm{~A}$ study showed that low-energy $660 \mathrm{~nm}$ red GaAlAs laser irradiation at different energy levels affected the physiological and molecular characteristics of the mouse bone marrow stromal cells and enhanced the expression of BMP2 and IGFI, increasing proliferation and differentiation to the osteoblast cell. It was revealed that LLLT dosedependently increased osteoblast differentiation and mineral deposition. ${ }^{44}$

Cardiovascular disease is one of the leading causes of death in the world. New therapeutic approaches help reduce the size of the scar. In the final stage of the disease, cardiac transplantation is considered to have problems. Among therapeutic approaches, the stem cells that can overcome the defects caused by the disease are used. A study showed that the use of a low-level laser (780-950 $\mathrm{nm}, 10-50 \mathrm{~J} / \mathrm{cm}^{2}$ ) every day or every other day could be effective in treating the mesenchymal cells and increasing the survival, proliferation and homing of the MSCs. ${ }^{8}$ The use of an $810 \mathrm{~nm}$ low-power laser significantly reduced the infarct size and significantly increased the proliferation of the cells. ${ }^{45}$ The use of a low-power laser $\left(0.5 \mathrm{~J} / \mathrm{cm}^{2}\right)$ could promote the proliferation of the MSCs and their myogenic differentiation and facilitate the secretion of VEGF and NGF. ${ }^{46}$ A low-level laser (660 $\mathrm{nm}, 5 \mathrm{~mW}, 6,10,12 \mathrm{~J} / \mathrm{cm}^{2}$ ) could significantly increase the proliferation and viability of the bone marrow MSCs in the ROS. ${ }^{47}$ In another study, using low-level laser promotes the proliferation and differentiation of bone marrow-derived MSCs $(470 \mathrm{~nm}, 630 \mathrm{~nm}$, and $660 \mathrm{~nm}){ }^{48}$ The ischemia caused by myocardial infarction causes damage to the heart tissue that limits the capacity for the regeneration and restoration of the heart. Accordingly, the use of a $10 \mathrm{~mW} / \mathrm{cm}^{2}$ low-power laser triggers the migration of the bone marrow MSCs to the tissue of the ischemia that can improve its function. ${ }^{49}$ The treatment of the bone marrow MSCs from rats with a low-power laser $\left(5 \mathrm{~mW} / \mathrm{cm}^{2}, 15 \mathrm{~mW} / \mathrm{cm}^{2}\right)$ increased the proliferation and stimulated osteogenic differentiation in them. ${ }^{50} \mathrm{~A}$ low-power laser with high energy density would reduce the proliferation of the MSCs and could also inhibit the cytotoxic effects of carboplatin, cytarabine, paclitaxel, and vincristine drugs. ${ }^{51} \mathrm{~A}$ low-power laser $(808 \mathrm{~nm}, 4$
$\mathrm{J} / \mathrm{cm}^{2}$ ) would differentiate the bone marrow MSCs into osteoclasts and osteoblast..$^{52} \mathrm{~A}$ low-power laser (3 or $6 \mathrm{~J} /$ $\mathrm{cm}^{2}, 810 \mathrm{~nm}$ ) differentiated the bone marrow stem cells into neurons, and another low-power laser $(810 \mathrm{~nm}, 2$ or $4 \mathrm{~J} / \mathrm{cm}^{2}$ ) differentiated them into the osteoblast cells. ${ }^{53}$ In another study, the effect of a $635 \mathrm{~nm}$ diode laser on the proliferation of the bone marrow-derived MSCs was examined and the results showed that the proliferation of these cells significantly increased after using low-level laser irradiation due to the MSC proliferation dependence on Kir channel activity. The activation of Notch-1 pathway and its upregulation played an important role in this process. It was also revealed that using LLL not only activated Kir channels and stimulate Notch-1 signaling pathways but also coordinate upstream and downstream signaling of cell cycle regulators and induce mitogenic effects in the laser-irradiated cells (Table 1). ${ }^{54}$

\section{Mesenchymal Stem Cells Derived From Dental Pulp}

Dental pulp stem cells have fibroblastic morphology and self-renewal and are able to differentiate to different types of cells. ${ }^{55}$ Encapsulating the pulp stem cells and loading rhbmp4 in them and then low-power laser irradiation significantly increased osteogenic and odontogenic differentiation. A low-power laser increased the selfrenewal and survival of the pulpal stem cells. ${ }^{56}$ In these patients, engineering strategies were developed for the development of the alveolar bone. Therefore, the use of the stem cells for bone formation and its reconstruction required differentiation into the bone. A study also showed that the use of a low-power laser ( $5 \mathrm{~J}, 10 \mathrm{~J}, 20$ $\mathrm{J})$ increased osteogenic differentiation in the dental pulp stem cells..$^{55}$

\section{Blood Mesenchymal Stem Cells}

The repair of a damaged tendon is poor due to the dense extracellular matrix that uses the MSCs to repair the damaged tendon. A study showed that the human blood MSCs could be differentiated into tenocyte cells by a low-level laser; thus, the use of the growth factors such as EGF2, TGFB3, IGF-1, and Bfgf2 with a low-level laser could cause the expression of the most important tenogenic genes, including EGR1, TNV, and DCN. ${ }^{57}$

\section{Conclusion}

Adjusting different parameters of a laser is effective in the proliferation, differentiation, and migration of the MSCs and in general, a low-power laser will be able to have a positive effect on the MSCs, helping to improve different disease models.

\section{Ethical Considerations}

This study has been approved by the ethical committee of Shahid Beheshti University of Medical Sciences.

\section{Conflict of Interests}

The authors declare no conflict of interest. 


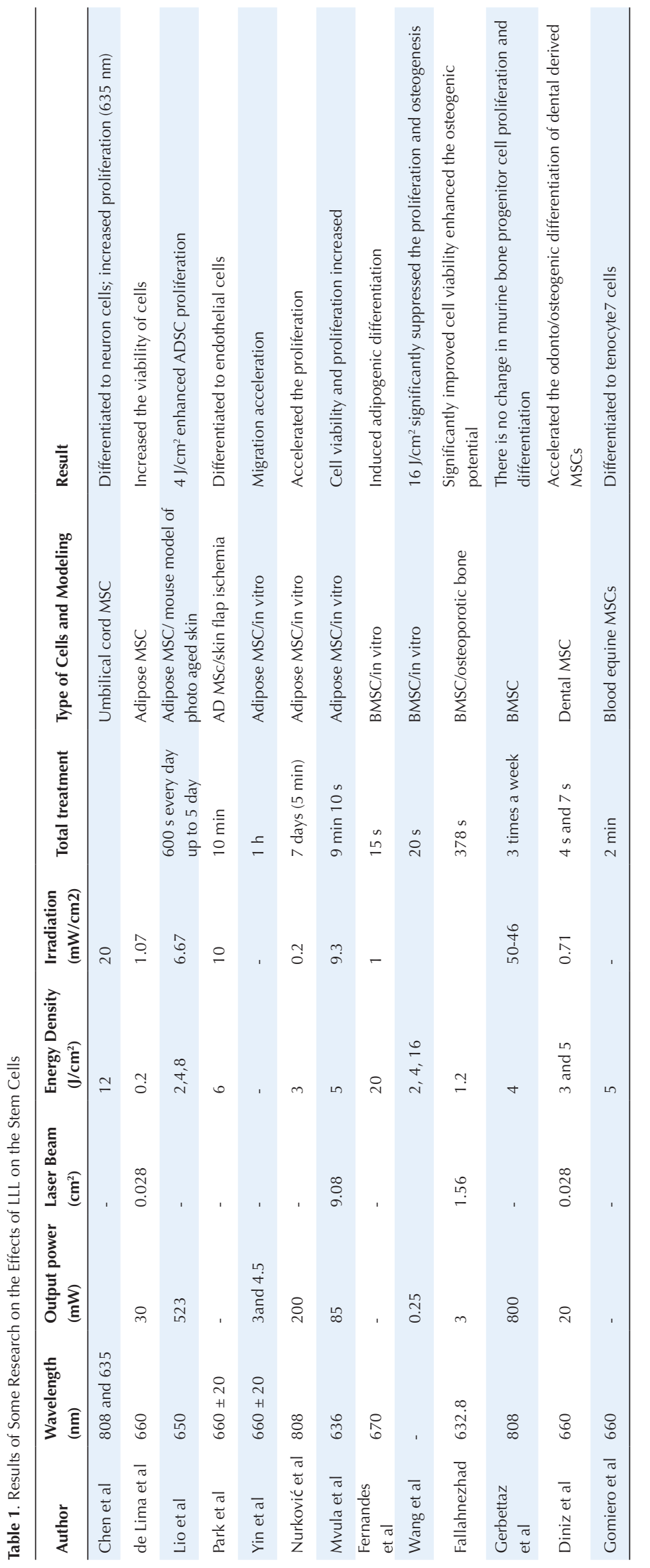




\section{Acknowledgment}

This work was supported by the Laser Application Research Center of Shahid Beheshti University of Medical Sciences, Tehran, Iran. We would like to thank the Hearing Disorders Research Center of Loghman Hakim Hospital, Tehran, Iran.

\section{References}

1. Hamblin MR, Huang Y. Handbook of Photomedicine. Boca Raton: CRC Press; 2013.

2. Saadati F, Mahdikia H, Abbaszadeh HA, Abdollahifar MA, Khoramgah MS, Shokri B. Comparison of direct and indirect cold atmospheric-pressure plasma methods in the B 16 F 10 melanoma cancer cells treatment. Sci Rep. 2018;8(1):7689.

3. Zarei M, Wikramanayake TC, Falto-Aizpurua L, Schachner LA, Jimenez JJ. Low level laser therapy and hair regrowth: an evidence-based review. Lasers Med Sci. 2016;31(2):36371. doi: 10.1007/s10103-015-1818-2.

4. Kim K, Lee J, Jang H, Park S, Na J, Myung JK, et al. Photobiomodulation Enhances the Angiogenic Effect of Mesenchymal Stem Cells to Mitigate Radiation-Induced Enteropathy. Int J Mol Sci. 2019;20(5): 1131. doi: 10.3390/ ijms20051131.

5. Liao X, Li SH, Xie GH, Xie S, Xiao LL, Song JX, et al. Preconditioning With Low-Level Laser Irradiation Enhances the Therapeutic Potential of Human Adiposederived Stem Cells in a Mouse Model of Photoaged Skin. Photochem Photobiol. 2018;94(4):780-90. doi: 10.1111/ php.12912.

6. Han B, Fan J, Liu L, Tian J, Gan C, Yang Z, et al. Adiposederived mesenchymal stem cells treatments for fibroblasts of fibrotic scar via downregulating TGF- $\beta 1$ and Notch-1 expression enhanced by photobiomodulation therapy. Lasers Med Sci. 2019;34(1):1-10. doi: 10.1007/s10103-0182567-9.

7. Borzabadi-Farahani A. Effect of low-level laser irradiation on proliferation of human dental mesenchymal stem cells; a systemic review. J Photochem Photobiol B. 2016;162:57782. doi: 10.1016/j.jphotobiol.2016.07.022.

8. El Gammal ZH, Zaher AM, El-Badri N. Effect of lowlevel laser-treated mesenchymal stem cells on myocardial infarction. Lasers Med Sci. 2017;32(7):1637-46. doi: 10.1007/s10103-017-2271-1.

9. Zecha JA, Raber-Durlacher JE, Nair RG, Epstein JB, Sonis ST, Elad S, et al. Low level laser therapy/photobiomodulation in the management of side effects of chemoradiation therapy in head and neck cancer: part 1: mechanisms of action, dosimetric, and safety considerations. Support Care Cancer. 2016;24(6):2781-92. doi: 10.1007/s00520-0163152-z.

10. Gao X, Xing D. Molecular mechanisms of cell proliferation induced by low power laser irradiation. J Biomed Sci. 2009;16(1):4.

11. Ganjali M, Seifalian AM, Mozafari M. Effect of laser irradiation on cell cycle and mitosis. J Lasers Med Sci. 2018;9(4):249.

12. Shefer G, Barash I, Oron U, Halevy O. Low-energy laser irradiation enhances de novo protein synthesis via its effects on translation-regulatory proteins in skeletal muscle myoblasts. Biochim Biophys Acta. 2003;1593(2-3):131-9 . doi: 10.1016/s0167-4889(02)00350-6.

13. Wu YH, Wang J, Gong DX, Gu HY, Hu SS, Zhang $\mathrm{H}$. Effects of low-level laser irradiation on mesenchymal stem cell proliferation: a microarray analysis. Lasers Med Sci. 2012;27(2):509-19. doi: 10.1007/s10103-011-0995-x.

14. Deng C, Liu G. The PI3K/Akt signalling pathway plays essential roles in mesenchymal stem cells. Br Biomed Bull. 2017;5(2):301.

15. Chen $\mathrm{CH}$, Hung HS, Hsu SH. Low-energy laser irradiation increases endothelial cell proliferation, migration, and eNOS gene expression possibly via PI3K signal pathway. Lasers Surg Med. 2008;40(1):46-54. doi: 10.1002/lsm.20589.

16. Szymczyszyn A, Doroszko A, Szahidewicz-Krupska E, Rola P, Gutherc R, Jasiczek J, et al. Effect of the transdermal lowlevel laser therapy on endothelial function. Lasers Med Sci. 2016;31(7):1301-7. doi: 10.1007/s10103-016-1971-2.

17. Araújo TG, Oliveira AG, Franchi Teixeira AR. Low-Power Laser Irradiation (LPLI): a clinical point of view on a promising strategy to improve liver regeneration. J Lasers Med Sci. 2018;9(4):223-7. doi: 10.15171/jlms.2018.40.

18. Braun DC, Garfield SH, Blumberg PM. Analysis by fluorescence resonance energy transfer of the interaction between ligands and protein kinase $\mathrm{C} \delta$ in the intact cell. J Biol Chem. 2005;280(9):8164-71. doi: 10.1074/jbc. M413896200.

19. Zhang J, Xing D, Gao X. Low-power laser irradiation activates Src tyrosine kinase through reactive oxygen species-mediated signaling pathway. J Cell Physiol. 2008;217(2):518-28. doi: 10.1002/jcp.21529.

20. Yin K, Zhu R, Wang S, Zhao RC. Low-level laser effect on proliferation, migration, and antiapoptosis of mesenchymal stem cells. Stem Cells Dev. 2017;26(10):762-75. doi: $10.1089 / \mathrm{scd} .2016 .0332$.

21. Rai V. Role of Reactive Oxygen Species in Low-Level Laser Therapy. Handbook of Low-Level Laser Therapy. Pan Stanford; 2016. p. 177-200.

22. Kerdari M, Behnam GH, Farhadi M, Masoumipoor M, Hassanzadeh S, Soleimani M, et al. Effects of 660nm LowLevel Laser Therapy on P2X3 Expression of Lumbar DRG of Adult Male Rats with Neuropathic Pain. Int Clin Neurosci J. 2016;3(4):193-200. doi: 10.22037/icnj.v3i4.16119.

23. Wang L, Wu F, Liu C, Song Y, Guo J, Yang Y, et al. Lowlevel laser irradiation modulates the proliferation and the osteogenic differentiation of bone marrow mesenchymal stem cells under healthy and inflammatory condition. Lasers Med Sci. 2019;34(1):169-78. doi: 10.1007/s10103018-2673-8.

24. Ferreira-Silva V, Primo FL, Baqui MMA, Magalhães DAR, Orellana MD, Castilho-Fernandes A, et al. Beneficial role of low-intensity laser irradiation on neural $\beta$-tubulin III protein expression in human bone marrow multipotent mesenchymal stromal cells. Stem Cell Rev Rep. 2018;14(4):585-98. doi: 10.1007/s12015-017-9796-3.

25. Chen $\mathrm{H}, \mathrm{Wu} \mathrm{H}$, Yin $\mathrm{H}$, Wang J, Dong H, Chen Q, et al. Effect of photobiomodulation on neural differentiation of human umbilical cord mesenchymal stem cells. Lasers Med Sci. 2019;34(4):667-75. doi: 10.1007/s10103-018-2638-y.

26. Chen H, Wang H, Li Y, Liu W, Wang C, Chen Z. Biological effects of low-level laser irradiation on umbilical cord mesenchymal stem cells. AIP Advances. 2016;6(4):045018. 
doi: 10.1063/1.4948442.

27. de Lima RDN, Vieira SS, Antonio EL, Camillo de Carvalho PT, de Paula Vieira R, Mansano BSDM, et al. Low-level laser therapy alleviates the deleterious effect of doxorubicin on rat adipose tissue-derived mesenchymal stem cells. $J$ Photochem Photobiol B. 2019;196:111512. doi: 10.1016/j. jphotobiol.2019.

28. Lucke LD, Bortolazzo FO, Theodoro V, Fujii L, Bombeiro $\mathrm{AL}$, Felonato M, et al. Low-level laser and adipose-derived stem cells altered remodelling genes expression and improved collagen reorganization during tendon repair. Cell Prolif. 2019;52(3):e12580. doi: 10.1111/cpr.12580.

29. Park IS, Chung PS, Ahn JC, Leproux A. Human adiposederived stem cell spheroid treated with photobiomodulation irradiation accelerates tissue regeneration in mouse model of skin flap ischemia. Lasers Med Sci. 2017;32(8):1737-46. doi: 10.1007/s10103-017-2239-1.

30. Park IS, Chung PS, Ahn JC. Angiogenic synergistic effect of adipose-derived stromal cell spheroids with low-level light therapy in a model of acute skin flap ischemia. Cells Tissues Organs. 2016;202(5-6):307-18. doi: 10.1159/000445710.

31. Park IS, Chung PS, Ahn JC. Enhancement of ischemic wound healing by spheroid grafting of human adiposederived stem cells treated with low-level light irradiation. PLoS One. 2015;10(6):e0122776. doi: 10.1371/journal. pone.0122776.

32. Nurković J, Zaletel I, Nurković S, Hajrović Š, Mustafić F, Isma J, et al. Combined effects of electromagnetic field and low-level laser increase proliferation and alter the morphology of human adipose tissue-derived mesenchymal stem cells. Lasers Med Sci. 2017;32(1):15160. doi: 10.1007/s10103-016-2097-2.

33. Mvula B, Abrahamse H. Differentiation potential of adipose-derived stem cells when cocultured with smooth muscle cells, and the role of low-intensity laser irradiation. Photomed Laser Surg. 2016;34(11):509-15. doi: 10.1089/ pho.2015.3978.

34. Barboza CAG, Ginani F, Soares DM, Henriques ÁCG, Freitas Rde A. Low-level laser irradiation induces in vitro proliferation of mesenchymal stem cells. Einstein (Sao Paulo). 2014;12(1):75-81. doi: 10.1590/S167945082014AO2824.

35. Park IS, Chung PS, Ahn JC. Enhanced angiogenic effect of adipose-derived stromal cell spheroid with low-level light therapy in hind limb ischemia mice. Biomaterials. 2014;35(34):9280-9. doi: 10.1016/j. biomaterials.2014.07.061.

36. Choi K, Kang BJ, Kim H, Lee S, Bae S, Kweon OK, et al. Low-level laser therapy promotes the osteogenic potential of adipose-derived mesenchymal stem cells seeded on an acellular dermal matrix. J Biomed Mater Res B Appl Biomater. 2013;101(6):919-28. doi: 10.1002/jbm.b.32897.

37. Castilho-Fernandes A, Lopes TG, Ferreira FU, Rezende N, Silva VF, Primo FL, et al. Adipogenic differentiation of murine bone marrow mesenchymal stem cells induced by visible light via photo-induced biomodulation. Photodiagnosis Photodyn Ther. 2019;25:119-27. doi: 10.1016/j.pdpdt.2018.11.013.

38. Sefati N, Abbaszadeh HA, Fathabady FF, Abdollahifar MA, Khoramgah MS, Darabi S, et al. The combined effects of mesenchymal stem cell conditioned media and low-level laser on stereological and biomechanical parameter in hypothyroidism rat model. J Lasers Med Sci. 2018;9(4):243.

39. AlGhamdi KM, Kumar A, Moussa NA. Low-level laser therapy: a useful technique for enhancing the proliferation of various cultured cells. J Lasers Med Sci. 2012;27(1):23749.

40. Fallahnezhad S, Piryaei A, Tabeie F, Nazarian H, Darbandi $\mathrm{H}$, Amini A, et al. Low-level laser therapy with heliumneon laser improved viability of osteoporotic bone marrowderived mesenchymal stem cells from ovariectomy-induced osteoporotic rats. J Biomed Opt. 2016;21(9):098002 . doi: 10.1117/1.JBO.21.9.098002.

41. Amaroli A, Agas D, Laus F, Cuteri V, Hanna R, Sabbieti MG, et al. The effects of photobiomodulation of $808 \mathrm{~nm}$ diode laser therapy at higher fluence on the in vitro osteogenic differentiation of bone marrow stromal cells. Front Physiol. 2018;9:123. doi: 10.3389/fphys.2018.00123.

42. Tuby H, Maltz L, Oron U. Implantation of low-level laser irradiated mesenchymal stem cells into the infarcted rat heart is associated with reduction in infarct size and enhanced angiogenesis. Photomed Laser Surg. 2009;27(2):227-33. doi: 10.1089/pho.2008.2272.

43. Leonida A, Paiusco A, Rossi G, Carini F, Baldoni M, Caccianiga G. Effects of low-level laser irradiation on proliferation and osteoblastic differentiation of human mesenchymal stem cells seeded on a threedimensional biomatrix: in vitro pilot study. Lasers Med Sci. 2013;28(1):125-32. doi: 10.1007/s10103-012-1067-6.

44. Wu JY, Wang YH, Wang GJ, Ho ML, Wang CZ, Yeh ML, et al. Low-power GaAlAs laser irradiation promotes the proliferation and osteogenic differentiation of stem cells via IGF1 and BMP2. PloS One. 2012;7(9):e44027. doi: 10.1371/journal.pone.0044027.

45. Tuby H, Maltz L, Oron U. Low-level laser irradiation (LLLI) promotes proliferation of mesenchymal and cardiac stem cells in culture. Lasers Surg Med. 2007;39(4):373-8. doi: 10.1002/lsm.20492.

46. Hou JF, Zhang H, Yuan X, Li J, Wei YJ, Hu SS. In vitro effects of low-level laser irradiation for bone marrow mesenchymal stem cells: Proliferation, growth factors secretion and myogenic differentiation. Lasers Surg Med. 2008;40(10):726-33. doi: 10.1002/lsm.20709.

47. Cavalcanti MF, Maria DA, de Isla N, Leal-Junior EC, Joensen J, Bjordal JM, et al. Evaluation of the proliferative effects induced by low-level laser therapy in bone marrow stem cell culture. Photomed Laser Surg. 2015;33(12):610-6. doi: 10.1089/pho.2014.3864.

48. Ahn JC, Rhee YH, Choi SH, Kim DY, Chung PS. Low level light promotes the proliferation and differentiation of bone marrow derived mesenchymal stem cells. In Mechanisms for Low-Light Therapy X; 2015: International Society for Optics and Photonics.

49. Tuby H, Maltz L, Oron U. Induction of autologous mesenchymal stem cells in the bone marrow by lowlevel laser therapy has profound beneficial effects on the infarcted rat heart. Lasers Surg Med. 2011;43(5):401-9. doi: 10.1002/lsm.21063.

50. Allameh M, Khalesi S, Khozeimeh F, Faghihian E. Comparative evaluation of the efficacy of laser therapy and fibroblastic growth factor injection on mucosal wound healing in rat experimental model. J Lasers Med Sci. 
2018;9(3):194.

51. Horvát-Karajz K, Balogh Z, Kovács V, Drrernat AH, Sréter L, Uher F. In vitro effect of carboplatin, cytarabine, paclitaxel, vincristine, and low-power laser irradiation on murine mesenchymal stem cells. Lasers Surg Med. 2009;41(6):463-9. doi: 10.1002/lsm.20791.

52. Bouvet-Gerbettaz S, Merigo E, Rocca JP, Carle GF, Rochet $\mathrm{N}$. Effects of low-level laser therapy on proliferation and differentiation of murine bone marrow cells into osteoblasts and osteoclasts. Lasers Surg Med. 2009;41(4):291-7. doi: 10.1002/lsm.20759.

53. Soleimani M, Abbasnia E, Fathi M, Sahraei H, Fathi Y, Kaka G. The effects of low-level laser irradiation on differentiation and proliferation of human bone marrow mesenchymal stem cells into neurons and osteoblastsan in vitro study. Lasers Med Sci. 2012;27(2):423-30. doi: 10.1007/s10103-011-0930-1.

54. Giannelli M, Chellini F, Sassoli C, Francini F, Pini A, Squecco R, et al. Photoactivation of bone marrow mesenchymal stromal cells with diode laser: effects and mechanisms of action. J Cell Physiol. 2013;228(1):172-81. doi: $10.1002 /$ jcp.24119.

55. Pinheiro CC, de Pinho MC, Aranha AC, Fregnani E, Bueno DF. Low Power Laser Therapy: A Strategy to Promote the Osteogenic Differentiation of Deciduous Dental Pulp Stem Cells from Cleft Lip and Palate Patients. Tissue Eng Part A. 2018;24(7-8):569-75. doi: 10.1089/ten.TEA.2017.0115.

56. Diniz IM, Carreira AC, Sipert CR, Uehara CM, Moreira MS, Freire L, et al. Photobiomodulation of mesenchymal stem cells encapsulated in an injectable rhBMP4-loaded hydrogel directs hard tissue bioengineering. J Cell Physiol. 2018;233(6):4907-18. doi: 10.1002/jcp.26309.

57. Gomiero C, Bertolutti G, Martinello T, Van Bruaene $\mathrm{N}$, Broeckx SY, Patruno M, et al. Tenogenic induction of equine mesenchymal stem cells by means of growth factors and low-level laser technology. Vet Res Commun. 2016;40(1):39-48. doi: 10.1007/s11259-016-9652-y. 